\title{
De Barsy syndrome
}

INSERM

\section{Source}

INSERM. (1999). Orphanet: an online rare disease and orphan drug data base. De Barsy syndrome. ORPHA:2962

De Barsy syndrome (DBS) is characterized by facial dysmorphism (down-slanting palpebral fissures, a broad flat nasal bridge and a small mouth) with a progeroid appearance, large and late-closing fontanel, cutis laxa (CL), joint hyperlaxity, athetoid movements and hyperreflexia, pre- and postnatal growth retardation, intellectual deficit and developmental delay, and corneal clouding and cataract. 